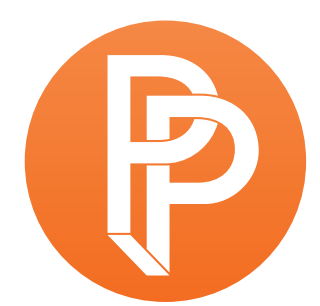

PERFORMANCE

PHILOSOPHY

\title{
THE DEATHS OF PAN
}

IOANA B. JUCAN BROWN UNIVERSITY

\section{PAN}

ECHO

THE PREFACE_READER

THE VOLUNTEER, THE DARK-HAIRED THIN VIRGIN, THE DRIVER, THE AUTOBIOGRAPHER = EXTRAS as CHARACTERS from other plays, mostly lovers, function as place-holders; all played by the same performer

Powercut 
Act I

ECHO (comes)

I am sorry

I am sorry

I am sorry

I'm sorry

I'm sorry

I'm sorry

sorry

(ECHO goes) 


\section{PREFACE_READER}

1663, state of M: "No person, householder or other shall spend his time idly or unprofitably, under pain of such punishment as the court shall think meet to inflict." The waste of time is a crime, because it's a rhyme: the force of necessity.

\section{PAN}

I am here. And there's also a chair on which I'm sitting. I am the one in the chair. Is the chair there even when I'm not sitting? I'm not a skeptic but I've learned to doubt.

As children,

Mortals learn how everything is,

To be grabbed and grasped,

Then mortals learn to doubt it... What if...

Damn the theatre!

I learn because I am. And I eat popcorn - triple white cheddar, triple white caramel ... it sparks my imagination.

A cynic is not a skeptic, History teaches us.

I don't need proofs other than the fact that I'm hungry. Putting on weight.

I don't have a weight,

I am a weight,

It's called gravity,

It's the law of attraction.

I have a sharp sense of hearing.

(an aside to the audience)

I hear my way through life, and I listen to reason.

I'm not getting paid to say this but it's not gratuitous:

The first performance artist of all times lived in a barrel,

Which he rolled around

From: place. To: place.

Enjoying the sun,

Asking spectators not to keep the sunshine from him.

Often he was begging. He was asked why he begged. He said: To teach people.

- Oh yeah? And what do you teach?

- Generosity. 
He was asked:

- Why do you take money from people?

- To show them how to spend their money. A piece of advice: Avoid some things in life.

- Why? Because. Money costs too much.

For a change, the city was under siege. All were busy fortifying the walls. Walls grow stronger if you make them. Everyone was working frantically. The first performance artist in history did not want to appear idle:

He rolled his barrel back and forth,

Back and forth,

Back and forth,

Back and forth,

Back and forth,

Back and forth,

Back and forth.

Force! It's called endurance. Growing muscles. The city fell.

I need an apple. I don't have the teeth to eat it. A child has beaten me in simplicity.

ECHO

I'm not getting my period.

PAN

Don't worry. I wouldn't if I were you.

Worry kills,

The divine touch of originality,

Growing to be who you are.

The first lesson I learned,

By the way,

The hard way.

I am self-taught. Life is the best teacher, for us all.

I'm one of us all.

PREFACE_READER

The waste of time: a crime.

$\mathrm{ECHO}$

I always had trouble picturing the two of us like the seated man thinking and the woman sitting next to the man, growing around the waist. I mean, strictly speaking: I've always had trouble picturing the two of us like the seated man thinking and the woman sitting next to the man, growing around the waist. 
PAN

We all get fat around our middles sooner or later in life. All factory food-eating peoples are now growing it a lot sooner, around the waist first. I don't know why. I agree it's unfair. It's just the way it is. Some things you just learn from looking around.

ECHO

No worries, I've learned to live with uncertainty. Picture that. Believe that.

PAN

One,

Who was soft-spoken,

Who said:

I believe that it is wishful thinking for anyone to expect a return to the good old days of [...], since change and [...], are the most common aspects of our times. What brings us together.

This being true, I came to realize that the important thing in life was to be flexible enough, to adjust to [...], whatever situation might arise. And above all, to learn to live with [...]. Revelations mortals have when they live with each other. To be and to learn.

ECHO

No, of course, I will stay by your side. No question here, please.

PAN

Natural, right. You are the one, the right one. You are.

I have the right to you. We have the right to be changing together, to watch how we change one another, to keep one another company while we're changing. That's gonna be our roles from now on.

On and on, and on, and on, and on and, on and on, and on and, on and on, and.

THE VOLUNTEER

A long laugh/And the emptiness/After that laugh.

(A laugh) 
PREFACE_READER

1948, state of U:

"Everyone has the right to property alone as well as in association with others, and no one shall be arbitrarily deprived of his property."

Properly: the force of necessity.

\section{PAN}

Hello all!

$\mathrm{ECHO}$

I'm going

PAN

Away

$\mathrm{ECHO}$

For a few days

\section{PAN}

I'm looking,

ECHO

Forrrr...

PAN

Someone

$\mathrm{ECHO}$

If someone could

PAN

Check on my cat, Rex

(THE DARK-HAIRED THIN VIRGIN strikes a match)

$\mathrm{ECHO}$

I live

PAN

Not far 
ECHO

Not far away

PAN

I'd need someone

PREFACE_READER

That's it: what we have in common.

ECHO

Stop by

PAN

Approximately once

$\mathrm{ECHO}$

A day

(THE DARK-HAIRED THIN VIRGIN stretches)

PAN

Just to make

ECHO

Sure

PAN

He has

ECHO

Food and water

PAN

And, and, and

ECHO

Litterbox

PAN

Clean

ECHO

Relatively 
(THE DARK-HAIRED THIN VIRGIN doesn't take directions well)

PAN

If you need

ECHO

Skip

PAN

A day

$\mathrm{ECHO}$

He'll be fine with it

PAN

Fine

ECHO

Large

PAN

A large bowl of food

ECHO

Food

(THE DARK-HAIRED THIN VIRGIN is cold)

PAN

All

ECHO

You

PAN

Can play with him

ECHO

Iffff...

PAN

You want 
ECHO

Butttttttttttttttttttttttttttttttttttttttttttttttttttttttttttttttttttttt...

PAN

Usually

ECHO

He hides

PAN

Strangers

$\mathrm{ECHO}$

Usually

PAN

Hides from strangers

PREFACE READER

Say: You're mine

PAN

I promise

$\mathrm{ECHO}$

Really

PAN

He is really

$\mathrm{ECHO}$

Cute

PAN

He is really cute

$\mathrm{ECHO}$

Iffffffffffffff...

PAN

If you can 
ECHO

$\mathrm{Him}$

PAN

Find him

ECHO

You

PAN

I

ECHO

I give you

PAN

I'll give

ECHO

You

PAN

88 dollars

ECHO

I have 57.13 pounds, worth 88.50 dollars. For sale at 50 percent discount: 44.25 dollars!

PREFACE_READER

Common though earth and all inferior creatures may be to everybody

Nobody, nobody has a right to the property one has in one's body,

one's own person

a mask.

The matter at hand: self-possession, property of labor:

The labor of one's body and the work of one's hands, we may say, are properly one's own.

PAN

Cheers.

THE DARK-HAIRED THIN VIRGIN

Two clocks/ ticking in the same room/ mean: "sure death."

(A room) 
PREFACE_READER

0 , state of O: "We are born with intense desire to touch, hunger to sense one another." Practice the good sense: the force of necessity.

PAN

I have just learned about someone who stole 500 pounds worth of chewing gum, to be able to pay for his journey home. May Hermes be with that person.

$\mathrm{ECHO}$

You shaved.

THE DRIVER

I rose/ with the dawn/

ECHO

To wish me all best.

The occasion: my birthday.

PAN

May that person find the way back after all that absence.

THE DRIVER

Well/ What do you/ think?

PREFACE_READER

We are here:

on earth:

to touch each other.

ECHO

Sweat makes one sticky: hair sticky.

THE DRIVER

/Look/

$\mathrm{ECHO}$

Look: Please, not today... 
PAN

May that person not stumble on the way.

$$
\begin{gathered}
\text { THE DRIVER } \\
\text { Let's just give it/ a try/ } \\
\text { I'll take care/ of everything/ } \\
\text { /after you leave/ }
\end{gathered}
$$

$\mathrm{ECHO}$

It's soft.

PAN

May you not get lost.

$$
\begin{aligned}
& \text { THE DRIVER } \\
& \text { /lt's soft/ }
\end{aligned}
$$

$$
\mathrm{ECHO}
$$

You have nothing to lose.

Nay, I don't have time today.

THE DRIVER

We'll be quick/ I promise/ Please/

$$
\mathrm{ECHO}
$$

Look, you don't know anything about me.

$$
\begin{aligned}
& \text { THE DRIVER } \\
& \text { /Tell me/ } \\
& \text { ECHO } \\
& \text { You tell me! }
\end{aligned}
$$

\section{PAN}

May you find your way.

$$
\begin{gathered}
\text { THE DRIVER } \\
\text { Okay/ } \\
\text { I am: }
\end{gathered}
$$

forty-nine years old/

I live:

all over the place/ 
Skills:

self-reliance/ self-direction/ resilience/

What I'm good at:

keeping in touch with people I know/ Faithfully yours/

And counting/ Keeping accounts/

And the art of flint knapping/ And the art of fire pit building/ And the art of tying good knots/

What I'm bad at:

getting drunk/ Never happens/ I get sick before I get drunk/

Experience:

I get paid by the hour /or by fixed-price bids/

Notable events in my life:

one day/ as I was driving home/ I saw something on the side of the road/ I pulled over/ A fallen branch/ I said to myself/ "This is the most beautiful sculpture I've ever seen"/ I took it home and let it rest in the basement/

All I know:

that either a proposition is true/ or its negation is/

It is not possible to be and not be the same thing/ except by way of an ambiguity/

Whatever is/is/

Ambiguity cannot exist in the facts themselves/

This is as simple as it can get/ Things are simple/

ECHO

It's not safe to cross the railroad tracks when a train is coming.

PREFACE_READER

The skin is the largest organ of the body: the body: is my skin: stay thin:

don't get:

thick-skinned:

under my skin.

THE DRIVER

/Cut the shit/ 
ECHO switches off.

THE DRIVER is turned on/

$\mathrm{ECHO}$ intends to leave.

THE DRIVER expects to be held by the hand/

ECHO remembers.

THE DRIVER reads a poem/

ECHO blinks.

THE DRIVER pauses/

ECHO blushes.

THE DRIVER sits/

ECHO thinks.

THE DRIVER makes himself understoodI

ECHO breathes.

THE DRIVER feels stoopid/

PREFACE_READER

Parents should caress or hug the child as much as 4-12 times a day: more or less. 
(PAN watches)

$\mathrm{ECHO}$

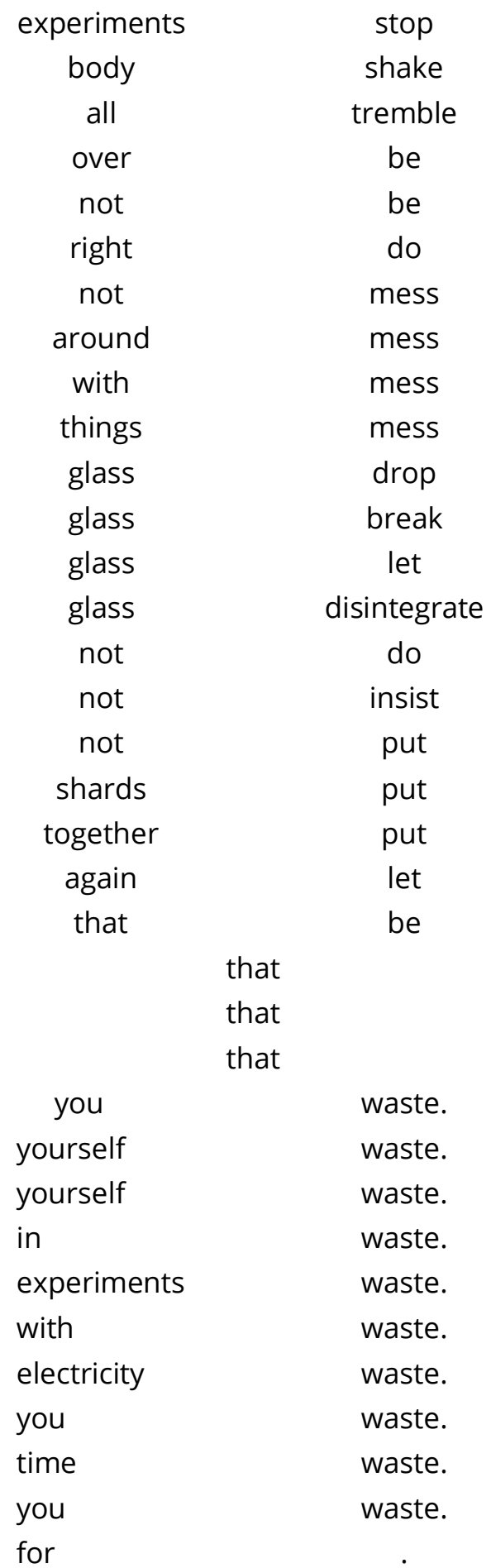




$\begin{array}{cc}\text { first } & \cdot \\ \text { time } & \cdot \\ \text { in } & \cdot \\ \text { life } & \cdot \\ \text { jealous } & \text { be. } \\ \text { jear } & \text { be. }\end{array}$

PREFACE_READER (whose mouth takes the shape of an " $O$ ") 2000, state of Y: O, 0 .

THE AUTOBIOGRAPHER

Be there /

love /

and be silent.

(A long silence) 
ECHO

In the beginning you wrote to me. You wrote emails to me. Then...

number two has committed suicide

I saw it coming. I thought it was you - but you stayed away, offline.

Someone made an announcement that he was selling pepper spray and other deterrents, while warning us to keep in mind that pepper spray is illegal for personal use in some cases.

hypocrisy unmasked

i feel like i want to gossip today and judge other people's personal lives - especially as they relate to you. i'd be a harsh, ruthless, heartless, judge.

mesmerize - to spellbind, fascinate

Chronicle of a Death Foretold, you see

I can't remember my first memory

what are you doing - how did you jump to these conclusions? What are you talking about?

make love in the bosom of nature, let's

strange bed-fellows we are and we've grown to admit it

I want it NOW, now - you hear; stipulate whatever you want. make it up. but I want it now - just so you know.

let's costume ourselves. and scare the shit out of them.

i think i feel closer to you now that you've set the clock back. spring forward, fall back

Does anyone have a pair of black mouse ears I can borrow for today? I'll trade a small bottle of spirits, if you like.

we're getting our first snow and i want to tell you that we're getting our first snow. i was right when $i$ told you that winter is in the air. i told you that winter is in the air before the weatherwoman predicted it. i was right. i deserve a kiss. or a candy. i wonder if you believed it when i said it to you. but i don't have the slightest idea if you care, so i'll tell it to you as a matter of fact - if i ever get the chance. before the snow melts and it all becomes pointless.

$i$ 'd be tempted to say that it's snowing as it does in fairytales - we sometimes say that - but $\mathrm{i}$ know of no fairytale in which it's snowing.

though it's snowing if you turn the glass globe i received as a birthday gift some years ago upside down and then you put it back in its normal position.

tonight, someone will be bathing in milk and sprinkling rose petals all over. donkey's milk keeps one young, so the books of the old say.

and now, guess what? someone's just posted a note about a lost notebook with scribblings about aesthetics and minimalism. asking if someone's spotted it. if so, it's mine, and i miss it, the person says. should this person be trusted? should this notebook be returned? it could be anywhere, really. now i'm curious if anyone'll find it. and return it. i, of course, have my doubts. that's only natural. 
i think i'm getting a cold 'cause i keep sneezing. right after i left i caught some kind of cold and i kept coughing whenever i talked and my voice was kind of hoarse. i think you were worried 'cause you asked if i have a cold. you were so sweet when you asked that it brings me to tears to even remember.

i sort of know that no word will come from you now as it's already late in your land. and it's getting early morning, but you like to sleep until late. we both know what i think about sleep and dreams but i don't want to offend you, so i won't reiterate. maybe i'll even grow to change my mind as i'm growing old.

this is probably the first love-letter i've sent in my whole life. and i'm sending it to a friend, not to my lover. tricky business, all this.

the wind blowing sounds like a dog barking. around here dogs don't bark. if they bark, dog owners get fined. things stay quiet most of the time. except for gunshots.

$i$ 'm forgetting the word. the last time we talked, i told you that you have forgotten because you are growing old. you laughed. but you were not quite awake, so I'm not sure you found it funny. my remark. note. idea.

work seems to heal. working, i forget. we talked about forgetting the last time we talked. i was doing my own thinking about forgetting (one another) as we were talking. fearfully. not something i enjoy double-thinking about but can't help it, somehow.

more than anything, and more than at any other time, I miss you when it rains. It rained all day today. and all night. funny how nature messes with my feelings. and with my state of mind. it was 5:05 as i thought this thought. now it's vanished. gone.

there there makes me think of mapping. interesting. but make the story short if you can. don't get derailed. off-tracks. stay focused so that you can go on.

i sleep but i'm missing the need to sleep. too much i sleep and too much i feel that i need to feel the need to sleep. sleeping without feeling the need is not the way to go. $i$ tell you. believe me. take note. and go on without sleeping.

i sleep because i'm cold. i came into the world sleeping and i go back to sleep whenever i'm cold or i miss you. which is maybe one and the same. let me put things together: the first time we slept together, the second time i slept in your arms and you were mad at me because of my underwear which i was still wearing. the moment you fell asleep - $\mathrm{i}$ felt it. your arms grew heavy and clung to my arms. that hurt. i did not move. i did not want to wake you up. endurance - that's what it's called. one might say. so. or maybe. perhaps. it was not. hard to say. hard to tell. none of us wants to talk about it. our narcissims and ourselves make good house together. together we live. but what endures? and i believe you've begun to refuse to write. because we're apart. the ocean. it's merely a crossing. but then i cross it and you remain in another land. this is the place for a sigh and a sob. but none of us wants the other to hear it. and there's the call. i've begun to believe in telepathy and all kinds of resonance, in hope you'll hear my call. there: i've opened my heart to you. sigh. sigh. lol.

and then it's hard to determine how much of life feels full and how much empty. not sure. will think about it. will let you know. we'll see. 
A Thunk is a beguiling question about everyday things that stops you in your tracks and helps you start to look at the world in a whole new light. derailed in the meantime, I met anonymous.

my mind is racing - it has been racing all day and now I am exhausted

\section{(munching an apple)}

compulsively comprehensively shitty day

$$
\text { and cold }
$$

The time has come, to reach a new realization 'tween me and you, time to clear the rumors, sensations, and things that just are untrue.

I don't think I've changed in any major way since I last saw you. I mean, strictly speaking. Since I've last seen you. was a long time ago. when i was younger a child a young child that's how I remembered things. A long time ago or a short while ago or now or not at all. but it was not as if it didn't happen if it was not at all it was just happening then and i was in the moment. this, i never got the chance to tell you. never found the right context. never had enough time. we were too busy. touching. ever since we've been trying to keep in touch.

\section{does it work?}

I don't know. i haven't quite figured that out. 'cause i didn't feel like it. but I need to be kind. be there and be kind my favorite line from a play i no longer remember. that play does not recognize itself as a play and denies itself as a novel. Also shows up in an out-of-print edition of an anatomy of melancholy. I am told. strictly speaking: farewell and be kind. meaning be well and be kind. And i'm missing my commas.

I quote. A lot. I quote myself to the point of exhaustion. I quote others to the point of exhaustion. I'm writing my autobiography to be able to move on. I want to go skating. It is cold. And I want to hold your hand while I'm skating. I am cold, and I'm holding your hand - meanwhile I'm skating. A functioning brain is not a lot more accessible than the center of the earth or the edge of the universe!

THE VOLUNTEER, THE DARK-HAIRED THIN VIRGIN, THE DRIVER, THE AUTOBIOGRAPHER\} EXTRAS as CHARACTERS\} (together)

Panic hit.

(Panic hits) 
ACT VII

To: PAN

From: ECHO 


\section{Author's note}

The sources from which the characters of "The Deaths of Pan" quote (sometimes from memory) include:

- A law regarding idleness passed by the Massachusetts General Court in 1633 (published in The book of the general lawes and libertyes concerning the inhabitants of the Massachusets, collected out of the records of the General Court, for the several years wherin they were made and established. And now revised by the same Court, and disposed into an alphabetical order, and published by the same authority in the General Court holden at Boston, in May 1649);

- Various accounts about Diogenes of Sinope;

- W. David Curtiss's essay, "To Live with Uncertainty";

- The Universal Declaration of Human Rights;

- John Locke's Second Treatise of Civil Government;

- Folklore;

- The Law of Excluded Middle;

- Ian Gilbert's The Little Book of Thunks (Wales, UK: Crown House Publishing, 2007);

- Sublime's song, New Realization;

- Jonathan Franzen's "My Father's Brain," published in New Yorker (September 10, 2001): 81-91;

- Various dictionaries and pieces of everyday conversation circulating through different digital and nondigital media.

\section{Biography}

Ioana B. Jucan is a researcher and performance-maker working at the intersection of theatre and performance, philosophy, and new media. Her scholarly and creative writing has been published in journals (TDR: The Drama Review, Nerve Lantern, Parallax, Liminalities, Revista Caracteres) and edited collections (Adorno and Performance, This and That: Essays on Live Art and Performance Studies). Her book of performance pieces, Cosmology of Worlds Apart, is forthcoming from O Balthazar Press. Jucan is currently completing a PhD in Theatre \& Performance Studies at Brown University.

(c) 2016 loana B. Jucan 